\title{
Lornoxicam, indomethacin and placebo: comparison of effects on faecal blood loss and upper gastrointestinal endoscopic appearances in healthy men
}

\author{
Steven J. Warrington', Nadia M.G. Debbas ${ }^{1}$, Michael Farthing ${ }^{2}$, Michael \\ Horton $^{2}$, Atholl Johnston ${ }^{2}$, Andrew Thillainayagam ${ }^{2}$, Paul Turner ${ }^{2}$ and $\mathrm{H}$. \\ Ferber $^{3}$
}

${ }^{1}$ Charterhouse Clinical Research Unit Limited, 91-93 Charterhouse Street, London EC1M 6HR, ${ }^{2} S t$ Bartholomew's Hospital, West Smithfield, London ECIA 7BE, UK and ${ }^{3}$ CL Pharma, Doerenkampgasse 4 A-1107 Vienna, Austria.

\begin{abstract}
Summary: Forty-five healthy men aged 21-34 years took part in a double-blind, parallel-group, placebo-controlled study of the effects of 28 days' treatment with lornoxicam $4 \mathbf{m g}$ twice daily or indomethacin $50 \mathrm{mg}$ twice daily on faecal blood loss and the endoscopic appearances of gastric and duodenal mucosa. After an initial endoscopic examination, subjects received, intravenously, on day $\mathbf{0}$, autologous erythrocytes labelled with ${ }^{51} \mathrm{Cr}$. Complete daily faecal collections were then made from days 6-12, 20-26 and 34-40. The drug treatments or placebo were given from days 13-41. Faecal blood loss was calculated from ${ }^{51} \mathrm{Cr}$-specific activity of blood and faeces. Endoscopy was repeated 4-8 hours after the last dose of medication; mucosal appearance was graded on a 5-point scale.

Lornoxicam caused no more adverse events than placebo; indomethacin caused more indigestion and central nervous system effects, and one subject in this group was withdrawn from the study. Median total blood losses during the pre-treatment and the second and fourth weeks of treatment were respectively 3.33, 3.95 and $5.71 \mathrm{ml}$ for lornoxicam, 2.87, 7.04 and $7.75 \mathrm{ml}$ for indomethacin, and 4.55, 3.64 and 4.13 $\mathrm{ml}$ for placebo. Differences between treatments were not statistically significant $(P=0.081$ for second week of treatment, $P=\mathbf{0 . 3 8 3}$ for fourth week of treatment; Kruskal-Wallis test).

The effect of chlortenoxicam on faecal blood loss in this study was thus intermediate between placebo and indomethacin, but within- and between-subject variability was such that the differences were not statistically significant. Endoscopic findings were normal in most subjects before and after all treatments, but indomethacin was associated with a slightly greater deterioration in endoscopic score and was the only treatment associated with Grade 3 appearance (in a single patient) in post-treatment endoscopy.
\end{abstract}

\section{Introduction}

Lornoxicam (previously called chlortenoxicam) is a new non-steroidal, anti-inflammatory drug belonging to the 'oxicam' chemical class. Lornoxicam has analgesic and anti-inflammatory activity in animal models with potency about 10 times that of either piroxicam or tenoxicam. The expected therapeutic dose is $\mathbf{4} \mathrm{mg}$ twice daily, and this dose has been well tolerated by young and elderly healthy volunteers. ${ }^{1}$ Lornoxicam is currently undergoing Phase 3 clinical trials.

Non-steroidal, anti-inflammatory drugs commonly cause indigestion, gastric erosions or peptic ulcer, and increased gastrointestinal occult blood

Correspondence: S.J. Warrington, M.A., M.B., B.Chir., M.D., M.R.C.P.

Accepted: 19 January 1990 loss. The present study aimed to compare the effects of lornoxicam with those of indomethacin and placebo on faecal blood loss and upper gastrointestinal endoscopic appearances in healthy men.

Subjects and methods

Forty-five (15 per treatment group) healthy male volunteers aged $21-35$ years, weight $50-90 \mathrm{~kg}$, participated in a double-blind, randomized, parallel-group study. All subjects claimed to have regular bowel habit (one or more stools per day) and all had acceptable findings on clinical history, physical examination, and routine blood biochemical and haematological screening tests and urinalysis. None had any evidence of past or present gastrointestinal disease. All subjects gave 
written consent to participate in the study, which was approved by the St Bartholomew's Hospital District Ethical Committee.

Between 3 and 7 days before study day 0 , volunteers underwent upper gastrointestinal endoscopy. All examinations were performed in the afternoon, with the subjects having fasted after a light early breakfast. Pre-medication was limited to 3-5 sprays of the pharynx with lignocaine hydrochloride (Xylocaine). The endoscope was passed via the mouth to the duodenum; duodenal and gastric mucosa was examined both on entry and on withdrawal, and the appearances scored as described by Lanza et al. $^{2}$ : Grade 0 - normal; Grade 1 - one submucosal haemorrhage or superficial ulceration; Grade 2 - more than one submucosal haemorrhage or superficial ulceration but not numerous or widespread; Grade 3 numerous areas of submucosal haemorrhage or superficial ulceration; Grade 4 - widespread involvement of the stomach with submucosal haemorrhage or superficial ulceration. Invasive ulcer of any size. (Invasive ulcer was defined as a lesion which produces an actual crater, i.e., a depression below the normal plane of the mucosal surface.)

On day 0 of the study, $10 \mathrm{ml}$ venous blood was taken from the subject, labelled with a maximum of $200 \mu \mathrm{Ci}{ }^{51} \mathrm{Cr}$ using standard methods ${ }^{3}$ and reinfused. The amount of radioactivity administered during this technique is about $50 \mu \mathrm{Ci}$. Six days were then allowed for the reinfused erythrocytes to appear in the faeces. All subjects then had a drug-free period from day 6 to day 12 during which complete stool collections were made daily.

From day 13-41 subjects were randomly allocated to one of the following 3 treatment groups: (1) lornoxicam $4 \mathrm{mg}$ twice daily; (2) indomethacin $50 \mathrm{mg}$ twice daily; (3) matching placebo twice daily.

The subjects were asked to take the medicine with meals, and to avoid taking breakfast cereals, any alcoholic drinks and any other medicines (including over-the-counter medications) during the entire study period.

Complete stool collections were made from days 20-26 and days 34-40 (second and fourth weeks of treatment). Venous blood samples $(10 \mathrm{ml})$ for determination of ${ }^{51} \mathrm{Cr}$-specific activity were taken on days 6, 20 and 34. Blood was taken into tubes containing $1.0 \mathrm{ml}$ acid-citrate-dextrose solution. The specific activity of the red cells, the haematocrit, and the activity of the faecal collections were determined and the whole blood content of each daily faecal collection was calculated. Counting was done using a Packard Tricarb scintillation spectrometer, Model 3002. Faecal samples were counted for 3 minutes, and for blood samples the time taken for 10,000 counts to be made was recorded. Faecal blood loss for each subject was calculated as $\mathrm{ml}$ whole blood lost during each day of the 7-day collection periods.

Tolerability assessments were made on days 20 , 27 and 34 . Adverse events were recorded, including subjects' response to the question 'how have you been feeling during the last week'.

Upper gastrointestinal endoscopy was repeated on the afternoon of day 41, 4-8 hours after the last dose of medication. Appearances were graded in the same way as at the initial examination.

\section{Statistical analysis}

Because volunteer subjects rarely produced a faecal sample on every day of all 3 collection periods, the faecal blood loss was totalled for each individual subject within each of the 3 collection periods. These data were then used in further statistical analyses. Between-group comparisons were made using non-parametric one-way analysis of variance (Kruskal-Wallis test). The data from each period were analysed separately. Within-group, betweenperiod comparisons were made using nonparametric 2-way analysis of variance (Friedman test). Significant differences were further analysed using the Wilcoxon matched pairs test for pairwise comparison of the treatment periods. The null hypothesis was rejected if $P<0.05$.

\section{Results}

Complete blood loss data and endoscopy results were obtained from 44 subjects. One subject was withdrawn from the study because of anxiety and restlessness following the first dose of indomethacin treatment, and he was not replaced; his results have been excluded from the analysis, since no assessments were made during treatment. Including this subject, 35 of the 45 subjects experienced adverse events during treatment: 11 receiving placebo, 11 lornoxicam, and 13 indomethacin. Of these subjects, 8 receiving placebo, 8 lornoxicam and 10 indomethacin had gastrointestinal symptoms; 6 receiving placebo, 5 lornoxicam and 9 indomethacin had indigestion; 4 receiving placebo, 4 lornoxicam and 6 indomethacin had central nervous system symptoms; and 3 subjects receiving each treatment experienced headaches.

\section{Faecal blood loss}

Table I shows the median daily blood loss for each treatment. Table II shows the median blood loss for each collection period and treatment, together with the results of the Kruskal-Wallis tests. Table III shows the results of the Friedman test and Wil- 
Table I Median daily blood loss for each treatment (ml)

\begin{tabular}{rccc}
\hline Day & Lornoxicam & Indomethacin & Placebo \\
\hline 6 & 0.320 & 0.430 & 0.485 \\
7 & 0.545 & 0.625 & 0.380 \\
8 & 0.220 & 0.285 & 0.890 \\
9 & 0.660 & 0.590 & 0.485 \\
10 & 0.300 & 0.555 & 1.010 \\
11 & 0.440 & 0.330 & 0.600 \\
12 & 0.320 & 0.310 & 0.635 \\
20 & 0.770 & 1.140 & 0.460 \\
21 & 0.525 & 1.110 & 0.790 \\
22 & 0.470 & 1.155 & 0.630 \\
23 & 0.645 & 1.080 & 0.580 \\
24 & 0.830 & 1.100 & 0.615 \\
25 & 0.760 & 1.050 & 0.600 \\
26 & 0.335 & 0.730 & 0.905 \\
34 & 1.020 & 2.275 & 1.100 \\
35 & 0.895 & 1.115 & 0.840 \\
36 & 0.715 & 1.095 & 0.870 \\
37 & 0.670 & 1.160 & 0.845 \\
38 & 0.490 & 0.975 & 1.010 \\
39 & 0.915 & 0.520 & 0.850 \\
40 & 0.820 & 0.980 & 0.745 \\
\hline
\end{tabular}

coxon matched pairs tests for within-treatment, between-period comparisons. Median blood losses were greater during indomethacin treatment than $\stackrel{\varnothing}{\AA}$ during lornoxicam treatment, which was in turn $\subseteq$ associated with a higher median blood loss than $\overrightarrow{\overrightarrow{\vec{A}}}$ was placebo. Nevertheless, the differences failed to reach statistical significance because of the variability of the data (Table II). Within-group comparison showed significant results only for the lornoxicam group (Table III).

\section{Endoscopic appearances}

The results from the subjects who had a score greater than zero in either of the endoscopic examinations are shown in Table IV. Most subjects had scores of zero both before and after treatment, and thus statistical analysis of these data was not undertaken.

Table II Median blood loss (range) for each collection period and treatment $(\mathrm{ml})$

\begin{tabular}{lccc}
\hline & $\begin{array}{c}\text { Pre-treatment } \\
\text { days 6-12 }\end{array}$ & $\begin{array}{c}\text { Treatment } \\
\text { days 20-26 }\end{array}$ & $\begin{array}{c}\text { Treatment } \\
\text { days 34-40 }\end{array}$ \\
\hline Placebo & 4.55 & 3.64 & 4.13 \\
& $(0.58-9.63)$ & $(1.04-10.63)$ & $(1.08-90.03)$ \\
Lornoxicam & 3.33 & 3.95 & 5.71 \\
& $(0.58-8.23)$ & $(0.95-12.17)$ & $(1.76-19.11)$ \\
Indomethacin & 2.87 & 7.04 & 7.75 \\
& $(0.70-14.51)$ & $(1.19-29.28)$ & $(3.66-14.32)$ \\
$\begin{array}{l}P \text { value for } \\
\text { differences } \\
\text { between treatments } \\
\text { (Kruskal-Wallis test) }\end{array}$ & & & \\
\hline
\end{tabular}

Table III Results of Friedman and Wilcoxon matched pairs tests for within-treatment, between-period comparisons

\begin{tabular}{|c|c|c|c|c|}
\hline & $\begin{array}{l}\text { Friedman test } \\
\text { between-periods }\end{array}$ & $\begin{array}{r}\text { Wilco } \\
\text { Day 20-26 } \\
\text { vs Day 6-12 }\end{array}$ & $\begin{array}{c}P \text { values } \\
\text { xon matched } \\
\text { Day } 34-40 \\
\text { vs Day 6-12 }\end{array}$ & $\begin{array}{l}\text { pairs test } \\
\text { Day } 20-26 \\
\text { vs Day } 34-40\end{array}$ \\
\hline Placebo & 0.4204 & - & - & - \\
\hline Chlortenoxicam & 0.015 & 0.0346 & 0.0045 & 0.1057 \\
\hline Indomethacin & 0.1353 & - & - & - \\
\hline
\end{tabular}


Table IV Endoscopy scores before and after treatment with placebo, lornoxicam and indomethacin

\begin{tabular}{|c|c|c|c|c|c|c|}
\hline & \multicolumn{2}{|c|}{$\begin{array}{c}\text { Placebo } \\
(\mathrm{n}=15)\end{array}$} & \multicolumn{2}{|c|}{$\begin{array}{l}\text { Lornoxicam } \\
(\mathrm{n}=15)\end{array}$} & \multicolumn{2}{|c|}{$\begin{array}{l}\text { Indomethacin } \\
(\mathrm{n}=14)\end{array}$} \\
\hline & Before & After & Before & After & Before & After \\
\hline & 0 & 1 & 0 & 2 & 0 & 1 \\
\hline & 0 & 1 & 0 & 1 & 0 & 2 \\
\hline & 0 & 2 & 2 & 0 & 0 & 3 \\
\hline & & & 1 & 2 & 0 & 2 \\
\hline & & & 0 & 2 & & \\
\hline $\begin{array}{l}\text { Total } \\
\text { scores }\end{array}$ & 0 & 4 & 3 & 7 & 0 & 8 \\
\hline
\end{tabular}

Results from subjects with zero scores throughout have been excluded.

\section{Discussion}

In this study, faecal blood loss was greatest during indomethacin treatment, intermediate during lornoxicam treatment, and least on placebo treatment. However, the difference between treatments failed to reach statistical significance at the conventional level $(P=0.0809$ for second week of treatment, $P=0.3828$ for fourth week of treatment, Kruskal-Wallis test). Examination of the raw data and median daily blood loss (Table I) shows that faecal blood loss on all treatments was variable and sporadic rather than consistent from day to day, and thus the absence of a significant difference between treatments might well be a false negative result. This conclusion is supported by the fact that comparison of faecal blood loss during treatment with that before treatment did show a significant difference for the group receiving lornoxicam. Since indomethacin caused greater median blood loss than either of the other 2 treatments, the absence of a statistically significant difference between blood loss before and during treatment with indomethacin must reflect greater variability of blood loss within the group.

Our results for blood loss during indomethacin treatment are consistent with 2 previous studies, 4,5 although neither of these was a double-blind, parallel-group comparison with placebo. Taking all these results together, it seems clear that indomethacin does increase faecal blood loss, but that variability within and between subjects means that many subjects might be required to yield a high probability of obtaining a statistically significant result.

The effect of lornoxicam on faecal blood loss has not been studied previously, but results have been published for the chemically-related drugs piroxicam and tenoxicam. Piroxicam was found to increase faecal blood loss in 3 studies, ${ }^{6-8}$ but in another study had no effect. ${ }^{9}$ Tenoxicam more than doubled mean faecal blood loss compared with a placebo run-in period ${ }^{6}$ and its effect was similar to that of piroxicam. Our results for lornoxicam are thus compatible with previous studies of piroxicam and tenoxicam.

Endoscopic examinations both before and after the study showed few abnormal results (Table IV). However, indomethacin treatment was associated with the greatest deterioration in total endoscopy score, and the only subject who had Grade 3 abnormalities on endoscopy at the end of the study had received indomethacin treatment. Overall, the minor endoscopic abnormalities in this study are consistent with the modest and variable effect of the drugs on faecal blood loss. The results of endoscopy examinations in our study cannot be compared directly with previous studies of indomethacin or drugs of the 'oxicam' class because of differences in study design. Endoscopy has been performed in volunteers ${ }^{2,10-12}$ and patients ${ }^{13,14}$ receiving indomethacin treatment, and in patients ${ }^{15}$ receiving piroxicam. However, the duration of treatment of volunteers in these studies was generally only 7 days, whereas in our study it was 28 days. This might explain why gastric mucosal damage in most of these studies was greater than in ours: local tolerance could possibly develop to non-steroidal, anti-inflammatory drugs during more prolonged administration. However, Svendsen et al. ${ }^{12}$ found that indomethacin caused only few gastric mucosal abnormalities, which is concordant with our own results.

In spite of the propensity of non-steroidal, anti-inflammatory drugs to cause dyspepsia, adverse events were no more common in the group receiving lornoxicam treatment than in subjects receiving placebo. Even indomethacin was not much worse tolerated than placebo, although one subject did have to be withdrawn because of anxiety and restlessness on this treatment.

\section{Acknowledgements}

We thank Dr Ralph Kohn, Dr Jeff Harper and Karen Foley of Advisory Services (Clinical \& General) Limited for their help in setting up this project. 


\section{References}

1. Ankier, S.I., Brimelow, A.E., Crome, P. et al. Chlortenoxicam pharmacokinetics in young and elderly human volunteers Postgrad Med J 1988, 64: 752-754.

2. Lanza, F.L., Royer, G.L. Jr, Nelson, R.S., Chen, T.T., Seckman, C.E. \& Rack, M.F. The effects of ibuprofen, indomethacin, aspirin, naproxen and placebo on the gastric mucosa of normal volunteers: a gastroscopic and photographic study. Dig Dis Sci, 1979, 24: 823-828.

3. Dacie, J.Y. \& Lewis, S.M. Practical Haematology, 6th edition. Churchill Livingstone, Edinburgh, 1984.

4. Bird, H.A., Hill, J., Ardley, R.G., McEvoy, M. \& Wright, V. A comparison of blood loss caused by two prolonged-release formulations of indomethacin ('Flexin Continus' and 'Indocid' R) in normal healthy male volunteers. Curr Med Res Opin 1988, 11: 4-9.

5. Salom, I.L., Jacob, G., Jallad, N., Perdomo, C.A., Mullane, J.F. \& Weidler, D. Gastrointestinal microbleeding associated with the use of etodolac, ibuprofen, indomethacin and naproxen in normal males. $J$ Clin Pharmacol 1984, 24: 240-246.

6. Bird, H.A., Hill, J., Haw, W.M., Dixon, J.S., Harris, P.A. \& Wright, V. A comparison of faecal blood loss caused by tenoxicam and piroxicam in normal healthy male volunteers. Curr Med Res Opin 1985, 9: 524-528.

7. Hooper, J.W., Anslow, J.A., Martin, W.S., Araujo, P. \& Darke, A. Faecal blood loss during isoxicam and piroxicam administration for 28 days. Clin Pharmacol Ther 1985, 38: 533-537.

8. Jallad, N.S., Sanda, M., Salom, I.L. et al. Gastrointestinal blood loss in arthritic patients receiving chronic dosing with etodolac and piroxicam. Am J Med Sci 1986, 292: 272-276.
9. Bianchine, J.R., Proctor, R.R \& Thomas, F.B. Piroxicam, aspirin and gastrointestinal blood loss. Clin Pharmacol Ther 1982, 32: 247-252.

10. Lanza., F.L., Umbenhauer, E.R., Nelson, R.S., Rack, M.F. Daurio, C.P. \& White, LA. A double-blind randomized placebo controlled gastroscopic study to compare the effects of indomethacin capsules and indomethacin suppositories on the gastric mucosa of human volunteers. $J$ Rheumatol 1982,9 415-419.

11. Lanza, F.L., Nelson, R.S. \& Greenberg, B.P. Effects of fenbufen, indomethacin, naproxen, and placebo on gastric mucosa of normal volunteers. A comparative endoscopic and photographic evaluation. Am J Med 1983, 75: 75-79.

12. Svendsen, L.B., Hansen, O.H. \& Johansen, A. A comparison of the effects of HP 549 (Isoxepac), indomethacin and acetylsalicylic acid (Aspirin) on gastric mucosa in man. Scand $J$ Rheumatol 1981, 10: 186-188.

13. Greb, W.H., von-Schrader, H.W., Cerlek, S., Dominis, M. Hauptmann, E. \& Zenic, N. Endoscopic studies of nabumetone in patients with rheumatoid arthritis. A comparative endoscopic and histological evaluation. Am J Med 1987, 83: 19-24.

14. Hansen, T.M., Matzen, P. \& Madsen, P. Endoscopic evaluation of the effect of indomethacin capsules and suppositories on the gastric mucosa in rheumatic patients. $J$ Rheumatol 1984, 11: 484-487.

15. Zoli, G., Pasquinelli, G., Bonvicini, F., Gasbarrini, G. \& Laschi, R. SEM study 1: Gastric and duodenal lesions induced by non-steroidal anti-inflammatory drugs (aspirin, piroxicam) in man. Int $J$ Tissue React 1986, 8: 47-53. 